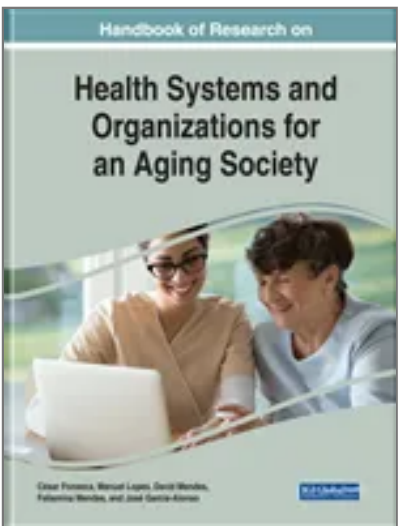

\title{
Handbook of Research on Health Systems and Organizations for an Aging Society
}

César Fonseca (Universidade de Évora, Portugal), Manuel José Lopes (Universidade de Évora, Portugal), David Mendes (Universidade de Évora, Portugal), Felismina Mendes (Universidade de Évora, Portugal) and José García-Alonso (University of Coimbra, Spain)

Release Date: August, 2019

Copyright: @ 2020

Pages: 323

ISBN13: 9781522598183

ISBN10: 1522598189

EISBN13: 9781522598190

DOI: 10.4018/978-1-5225-9818-3

Hardcover:

$\$ 292.00$

List Price: $\$ 365.00$

(/book/handbook-research-health-systems-organizations/223973?f=hardcover) (/book/handbook-research-health-systems-

E-Book:

$\$ 292.00$

List Price: $\$ 365.00$

organizations/223973?f=e-book) (/book/handbook-research-health-systems-organizations/223973?f=hardcover-e-book)

\section{Description}

Population aging is a growing challenge worldwide. As such, new models of provision, organization, and allocation of resources, particularly in healthcare, are needed. As the self-care and long-term care needs of this age group become more prevalent, the importance of improved health services and effective health management strategies are apparent.

The Handbook of Research on Health Systems and Organizations for an Aging Society provides emerging research exploring the challenges and opportunities for the development and management of health systems and organizations in relation to people aged 65 and over. Featuring coverage on a broad range of topics such as emotional wellness, long-term care, and professional caregiving, this book is ideally designed for health technicians, doctors, nurses, pharmacists, hospital administrators, clinical directors, laboratory technicians, medical professionals, researchers, and students.

\section{Topics Covered}

The many academic areas covered in this publication include, but are not limited to: 
- Artificial Intelligence

- Emotional Wellness

- Functional Independence

- Health Systems

- Healthcare Administration

- Long-Term Care

- Machine Learning

- Professional Caregiving

- Quality of Life

- Rehabilitation

\section{Table of Contents and List of Contributors}

Search this Book: Full text search terms

Reset

\begin{tabular}{|c|c|}
\hline Table of Contents & $\begin{array}{c}\text { View Full PDF (/pdf.aspx? } \\
\text { tid=238262\&ptid=223973\&ctid=15\&t=Table of } \\
\text { Contents\&isxn=9781522598183) }\end{array}$ \\
\hline Detailed Table of Contents & $\begin{array}{c}\text { View Full PDF }(/ p d f . a s p x ? \\
\text { tid=238263\&ptid=223973\&ctid=15\&t=Detailed } \\
\text { Table of Contents\&isxn=9781522598183) }\end{array}$ \\
\hline Preface & $\begin{array}{c}\text { View Full PDF (/pdf.aspx? } \\
\text { tid=238264\&ptid=223973\&ctid=15\&t=Preface\&isxn=9781522598183) }\end{array}$ \\
\hline
\end{tabular}

\section{Chapter 1}

Self-Perceived Health Status (/chapter/self-perceived-health-status/238266) (pages

1-11)

Maria Otília Zangão

Perceived health status is central to adequate health planning, not only because it plays a key role in health but also because it is related to the...

Sample PDF (/viewtitlesample. aspx?id=238266\&ptid=223973\&t=Self-Perceived Health Status\&isxn=9781522598183)

\section{Chapter 2}

Health Promotion and Wellness in Aging (/chapter/health-promotion-and-wellness-inaging/238267) (pages 12-28)

\section{Maria Cristina Campos de Sousa Faria}

The older population is growing and living longer than ever. That is why we must create more and more services suitable for this age group, so that...

Sample PDF ( $/$ viewtitlesample. aspx id=238267\&ptid=223973\&t=Health Promotion and Wellness in Aging\&isxn=9781522598183)

\section{Chapter 3}

Community-Led Ecosystem: A Promising Strategy to Strengthen Person-Centered Geriatric Care in Preventing Age-Related Dependency (/chapter/community-ledecosystem/238268) (pages 29-47)

Elzbieta Bobrowicz-Campos, Filipa Costa Couto, Luísa Teixeira-Santos, João Apóstolo

In this chapter, the triangulation analysis of connections between older adults, relevant stakeholders, and community will be made in order to...

Sample PDF (/viewtitlesample.aspx?id=238268\&ptid=223973\&t=Community-Led Ecosystem: A Promising Strategy to Strengthen Person-Centered Geriatric Care in Preventing Age-Related Dependency\&isxn=9781522598183) 


\section{Chapter 4}

Loneliness Among Rural Elderly: Present and Future Public Health Challenges

(/chapter/loneliness-among-rural-elderly/238269) (pages 48-61)

Borja Rivero Jiménez, Nuria María García Perales, David Conde Caballero, Beatriz Muñoz González, Julián F. Calderón García, Lorenzo Mariano Juarez

Population aging is a great challenge for modern societies at the future and is a central issue in the development of public policies. In Spain, in...

Sample PDF (/viewtitlesample. aspx?id=238269\&ptid=223973\&t=Loneliness Among Rural Elderly: Present and Future Public Health Challenges\&isxn=9781522598183)

\section{Chapter 5}

Developing and Managing Health Systems and Organizations for an Aging Society (/chapter/developing-and-managing-health-systems-and-organizations-for-an-agingsociety/238270) (pages 62-68)

\section{Ana Filipa Ramos, César Fonseca, Adriana Henriques}

With the worldwide trend towards aging and increasing numbers of chronic diseases, the promotion of self-care as a central issue in public health is...

Sample PDF (/viewtitlesample.aspx?id=238270\&ptid=223973\&t=Developing and Managing Health Systems and Organizations for an Aging Society\&isxn=9781522598183)

\section{Chapter 6}

Design of a Contact Assistive Robot for the Disabled, Elderly, and Infirm People: Case for Developing Countries (/chapter/design-of-a-contact-assistive-robot-for-thedisabled-elderly-and-infirm-people/238271) (pages 69-89)

Tawanda Mushiri, Panashe Adrian Mombeyarara, Thanks Marisa

The use of a wheelchair for normal routines or rehabilitation has various physiological and psychological implications. The use of contact assistive... Sample PDF (/viewtitlesample.aspx?id=238271\&ptid=223973\&t=Design of a Contact Assistive Robot for the Disabled, Elderly, and Infirm People: Case for Developing Countries\&isxn=9781522598183)

\section{Chapter 7}

Remote Monitoring and Recognition of Physical Activities of Elderly People Using Smartphone Accelerometer Sensor Data Using Deep Learning Models (/chapter/remote-monitoring-and-recognition-of-physical-activities-of-elderly-peopleusing-smartphone-accelerometer-sensor-data-using-deep-learning-models/238272) (pages 90-100)

\section{Govind P. Gupta, Shubham Gaur}

Remote monitoring and recognition of physical activities of elderly people within smart homes and detection of the deviations in their daily...

Sample PDF (/viewtitlesample.aspx?id=238272\&ptid=223973\&t=Remote Monitoring and Recognition of Physical Activities of Elderly People Using Smartphone Accelerometer Sensor Data Using Deep Learning Models\&isxn=9781522598183)

\section{Chapter 8}

Rehabilitation Nursing Program for Elderly Functional Independence (/chapter/rehabilitation-nursing-program-for-elderly-functional-independence/238274) (pages 102-114)

Rogério Ferrinho Ferreira, Luís Amador Ribeiro, César João Fonseca

To identify the gains in elderly functional independence through the implementation of the rehabilitation nursing program, a pilot study involving...

Sample PDF (/viewtitlesample. aspx?id=238274\&ptid=223973\&t=Rehabilitation Nursing

Program for Elderly Functional Independence\&isxn=9781522598183) 


\section{Chapter 9}

Gains From the Rehabilitation of Nursing to the Elderly With the Mobility Deficit by

Femur Fracture (/chapter/gains-from-the-rehabilitation-of-nursing-to-the-elderly-withthe-mobility-deficit-by-femur-fracture/238275) (pages 115-127)

Maria João Soares, Rogério Ferrinho Ferreira, João Vítor Vieira

The objective of this chapter is to identify the gains associated with rehabilitation nursing care implemented in the elderly person with mobility...

Sample PDF (/viewtitlesample. aspx?id=238275\&ptid=223973\&t=Gains From the

Rehabilitation of Nursing to the Elderly With the Mobility Deficit by Femur

Fracture\&isxn=9781522598183)

\section{Chapter 10}

Ability Assessment of the Elders to Manage Their Own Medication: A First Step for the Empowerment of the Geriatric Population (/chapter/ability-assessment-of-theelders-to-manage-their-own-medication/238276) (pages 128-151)

Ana M. Advinha, Carla Nunes, Manuel J. Lopes, Sofia Oliveira-Martins

About $45 \%$ of older people are unable to take their medicines as prescribed. Adherence represents a complex behavior that involves both the intention... Sample PDF (/viewtitlesample. aspx ?id=238276\&ptid=223973\&t=Ability Assessment of the Elders to Manage Their Own Medication: A First Step for the Empowerment of the Geriatric Population\&isxn=9781522598183)

\section{Chapter 11}

Learning to Live with Chronic Disease: Coronary Artery Disease (/chapter/learningto-live-with-chronic-disease/238277) (pages 152-166)

\section{Lisa Alves Gomes, Gorete Reis}

Cardiovascular diseases are chronic diseases with the highest morbidity and mortality rate worldwide. The high number of hospital admissions for...

Sample PDF (/viewtitlesample. aspx?id=238277\&ptid=223973\&t=Learning to Live with Chronic Disease: Coronary Artery Disease\&isxn=9781522598183)

\section{Chapter 12}

The Consequences of Comorbidity, Ischemic Heart Disease, and Stroke at the Functional Level in Elderly People at Home (/chapter/the-consequences-ofcomorbidity-ischemic-heart-disease-and-stroke-at-the-functional-level-in-elderlypeople-at-home/238278) (pages 167-175)

Maria do Céu Mendes Pinto Marques, Fátima Cano, Marta Carocinho

The objective of this chapter is to identify the consequences of comorbidity, ischemic heart disease, and functional stroke in elderly people at...

Sample PDF (/viewtitlesample. aspx id=238278\&ptid=223973\&t=The Consequences of Comorbidity, Ischemic Heart Disease, and Stroke at the Functional Level in Elderly People at Home\&isxn=9781522598183)

\section{Chapter 13}

Knowledge About HIV/AIDS: An Intergenerational Perspective (/chapter/knowledgeabout-hivaids/238279) (pages 176-184)

Ana Frias, Jorge Guerrero-Martin, Maria Barros, Maria Chora, Margarida Sim-Sim

Generations of young people, adults, and the elderly have or have had different ways of acquiring knowledge about HIVIAIDS. The accessibility of...

Sample PDF (/viewtitlesample. aspx id=238279\&ptid=223973\&t=Knowledge About HIVIAIDS: An Intergenerational Perspective\&isxn=9781522598183) 


\section{Chapter 14}

Prevalence of Cardiovascular Risk Factors in the Elderly Population of Alentejo: Integrative Review (/chapter/prevalence-of-cardiovascular-risk-factors-in-the-elderlypopulation-of-alentejo/238280) (pages 185-195)

Maria do Céu Mendes Pinto Marques, Ana Filipa Pereira Vaz, Ana Sofia Emídio Cardoso Leite, Cláudia Sofia Araújo, Cláudia Roque Condeço, José Ribeiro de Deus

The objective of this chapter is to identify cardiovascular risk factors in the elderly and their prevalence in the elderly population of Alentejo....

Sample PDF (/viewtitlesample.aspx?id=238280\&ptid=223973\&t=Prevalence of Cardiovascular Risk Factors in the Elderly Population of Alentejo: Integrative Review\&isxn=9781522598183)

\section{Chapter 15}

Falls in Elderly: A Hospital Reality Integrative Review (/chapter/falls-inelderly/238281) (pages 196-207)

Tânia Patrícia Cabo Relíquias, Carmen Dolores Roque Agostinho, Maria do Céu Marques

The objective of this chapter is to identify the risk factors and preponderant causes of falls in the hospital elderly inpatients. A survey on the...

Sample PDF (/viewtitlesample. aspx?id=238281\&ptid=223973\&t=Falls in Elderly: A Hospital

Reality Integrative Review\&isxn=9781522598183)

\section{Chapter 16}

Urinary Incontinence in the Elderly: The Importance of Self-Care Promotion

(/chapter/urinary-incontinence-in-the-elderly/238282) (pages 208-224)

Helena Maria Arco, Maria Arminda Costa

Urinarsy incontinence involves difficulty in retaining urine, making it a problem with multiple consequences. The purpose of this chapter is to...

Sample PDF (/viewtitlesample.aspx?id=238282\&ptid=223973\&t=Urinary Incontinence in the Elderly: The Importance of Self-Care Promotion\&isxn=9781522598183)

\section{Chapter 17}

Training Models for Formal Caregivers of Elderly Persons at Home: Studies and Gaps (/chapter/training-models-for-formal-caregivers-of-elderly-persons-athome/238284) (pages 226-246)

Lucília Mateus Nunes, Andreia Ferreri Cerqueira

The concern with the training models stems from our activity as teachers and researchers, recognizing the scenario of aging of the population, the...

Sample PDF (/viewtitlesample. aspx?id=238284\&ptid=223973\&t=Training Models for Formal Caregivers of Elderly Persons at Home: Studies and Gaps\&isxn=9781522598183)

\section{Chapter 18}

Burnout Among Formal Caregivers and Risk of Violence Against Institutionalized Elderly (/chapter/burnout-among-formal-caregivers-and-risk-of-violence-againstinstitutionalized-elderly/238285) (pages 247-262)

Susana Valido, Ermelinda do Carmo Caldeira, Felismina Mendes

Sociodemographic changes occurring in past decades are reflected as increased population aging, resulting in a higher need to institutionalize...

Sample PDF (/viewtitlesample.aspx?id=238285\&ptid=223973\&t=Burnout Among Formal Caregivers and Risk of Violence Against Institutionalized Elderly\&isxn=9781522598183) 


\section{Chapter 19}

Informal Cares and Caregivers in Rural Elderly: Emotional Costs in Public Health

Policies (/chapter/informal-cares-and-caregivers-in-rural-elderly/238286) (pages 263-

276)

Nuria María García Perales, Borja Rivero Jiménez, David Conde Caballero, Beatriz

Muñoz González, Lorenzo Mariano Juarez

The aging population means that health systems rely on informal carers to meet the physical, psychological, and emotional needs of older people. In...

Sample PDF (/viewtitlesample.aspx?id=238286\&ptid=223973\&t=Informal Cares and

Caregivers in Rural Elderly: Emotional Costs in Public Health

Policies\&isxn=9781522598183)

\section{About the Contributors}

View Full PDF (/pdf.aspx? tid $=238288 \&$ ptid $=223973 \&$ ctid $=17 \& \mathrm{t}=$ About the Contributors\&isxn=9781522598183)

Index
View Full PDF (/pdf.aspx? tid=238289\&ptid=223973\&ctid=17\&t=Index\&isxn=9781522598183)

\section{Learn More}

About IGI Global (/about/) | Partnerships (/about/partnerships/) | Contact (/contact/) | Job Opportunities (/about/staff/jobopportunities/) | FAQ (/faq/) | Management Team (/about/staff/)

\section{Resources For}

Librarians (/librarians/) | Authors/Editors (/publish/) | Distributors (/distributors/) | Instructors (/course-adoption/) | Translators (/about/rights-permissions/translation-rights/) | Editorial Services (/editorial-service-partners/)

\section{Media Center}

Webinars (/symposium/) | Blogs (/newsroom/) | Catalogs (/catalogs/) | Newsletters (/newsletters/)

\section{Policies}

Privacy Policy (/about/rights-permissions/privacy-policy/) | Cookie \& Tracking Notice (/cookies-agreement/) | Fair Use Policy (/about/rights-permissions/content-reuse/) | Ethics and Malpractice (/about/rights-permissions/ethics-malpractice/)

(http://www.facebook.com/pages//GI-Global/138206739534176?ref=sgm) ～(http://twitter.com/igiglobal) (https://www.linkedin.com/company/igiglobal)

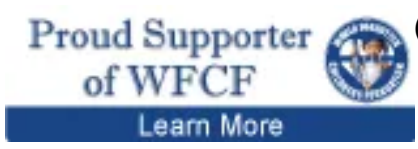
(http://www.world-forgotten-children.org) 